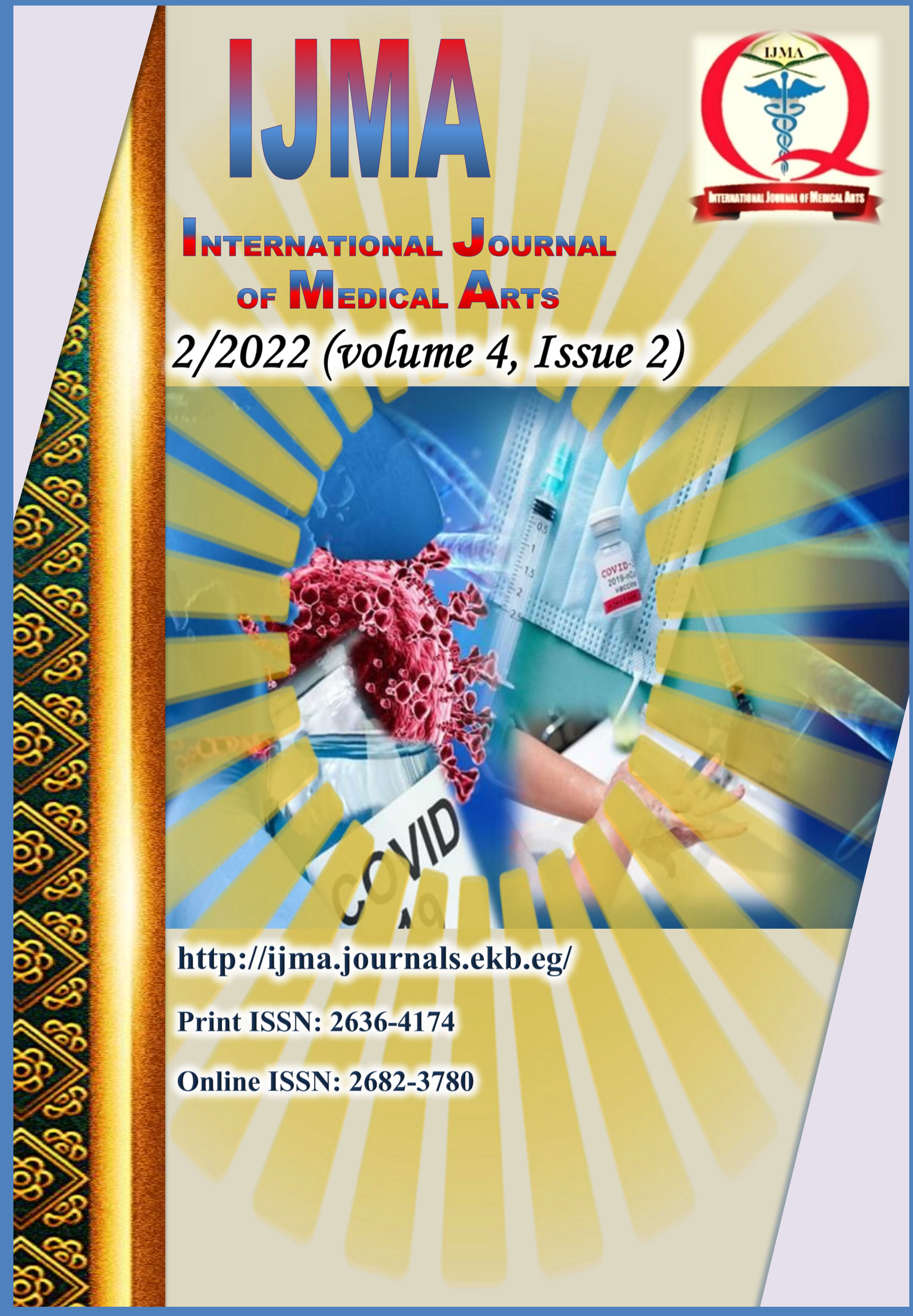





Available online at Journal Website
https://ijma.journals.ekb.eg/
Main Subject [Surgery]
Specific Subject [Neurosurgery]

Original Article

\title{
Outcome of Endoscopic Excision of the Third Ventricular Colloid Cyst
}

\author{
Abdel-Rahman Salah Abdel-Azeem Ibrahim ${ }^{*[1]}$, Hatem Mohamed Alsamoly ${ }^{[1]}$, \\ Mohamed Youssef ${ }^{[1]}$, Hamdy Mohammed Hussein ${ }^{[2]}$ \\ ${ }^{1}$ Department of Neurosurgery, Damietta Faculty of Medicine, Al-Azhar University, Egypt. \\ ${ }^{2}$ Department of Neurosurgery, Faculty of Medicine, Al-Azhar University, Cairo, Egypt.
}

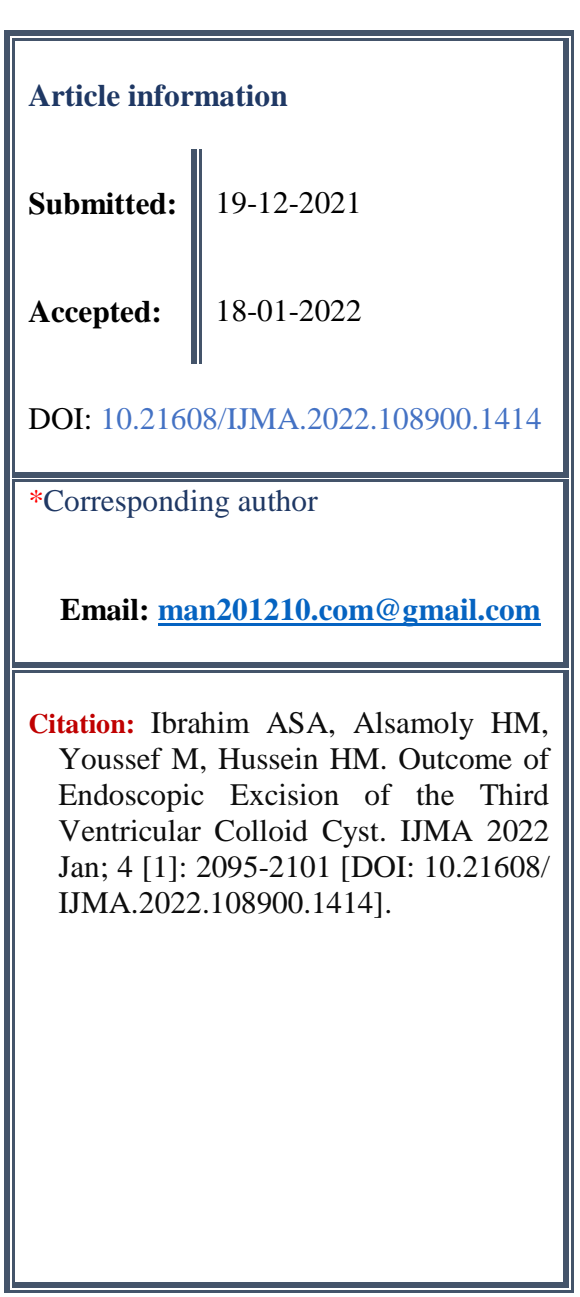

\begin{abstract}
Background: Colloid cyst of the third ventricle is not uncommon. The complete excision is crucial to relieve symptoms and prevent associated completions. Previously open excision was the role. However, the endoscopic approaches gained wide acceptance.
\end{abstract}

The aim of the work: The study aimed to assess the outcome of endoscopic excision of the third ventricular colloid cyst by symptoms resolution, excision extent and complications rate.

Patients and Methods: This is a retrospective study that covered the duration from February 2018 to February 2021. It included 20 subjects with a third ventricular colloid cyst, who managed by an endoscopic excision. Files were reviewed for preoperative evaluation [history, clinical neurological and ophthalmological examination] and radiological investigations to identify the cyst size, site, density and enhancement and the size of the third ventricle. Postoperatively, all patients were evaluated by general and neurological clinical examination, follow up imaging study immediately [second postoperative day], at 3 and 6 postoperative months. All complications and recurrence rate were documented, and results were graded on Barrow Neurological Institute scale.

Results: Males represented $60.0 \%$; the mean age was $37.5 \pm 11.3$ years. All had headache, $80.0 \%$ had blurred vision, and papilledema was recognized among $90.0 \%$. The average size of the cyst was $17.4 \pm 2.66 \mathrm{~mm}$. The total cyst removal was achieved for $85.0 \%$ and partial removal for $15.0 \%$. Postoperative infections were developed in 20.0\%. Three patients [15\%] had temporary amnesia and one patient [5\%] had intraventricular hemorrhage. All symptoms were resolved after surgery, except for three patients. Two of them [10\%] had mild visual disturbance and one had amnesia. The recurrence of the cyst was detected in 2 patients [10\%].

Conclusion: Endoscopic colloid cyst excision is an effective, safe and reliable technique with established learning curve.

Keywords: Colloid Cysts; Third Ventricle; Endoscopic; Recurrence; Barrow Neurological Institute Scale. 


\section{INTRODUCTION}

Colloid cysts [CCs] are defined as benign unilocular cysts originating from the neuroepithelium. It is consistently located in the anterior third ventricle. It represents 0.2 to $2.0 \%$ of all intracranial tumors ${ }^{[1,2]}$. Symptomatic cysts are usually reported in the patient's second to fifth decades of life and both genders are equally affected. Clinically, it could be asymptomatic, or presented with paroxysmal headache of different severity. Other presentations included drop attacks, dementia of progressive or fluctuating nature, hydrocephalus or sudden death due to obstruction of the foramen of Monro followed by acute hydrocephalus ${ }^{[3,4]}$.

Non-contrast computed tomography [CT] displays colloid cysts as a hypo-, iso-, or hyperdense, homogeneous and well-demarcated round or ovoid mass. The contrast enhancement is minimal or absent. They are discovered accidentally at a rate of 1 in 1,000 CT. By magnetic resonance imaging [MRI], CCs present as homogeneous to heterogeneous hypointense or hyperintense mass in $\mathrm{T} 1$ and $\mathrm{T} 2$ weighted sections. The outstanding characteristic is a sharply outlined round or ovoid mass in the anterior and superior third ventricle, besides or at the foramen of Monro. Hydrocephalus is reported as an association in most cases ${ }^{[1]}$.

Neuroimaging by CT and MRI simplifies and confirms the clinical diagnosis. Usually there is a round or ovoid lesion, with different densities or variable signals. These are different according to the viscosity and the concentration of cholesterol in cysts. The viscosity of the cyst can be initially analyzed using proper preoperative imaging, as it is well-defined as a predictive factor for difficult endoscopic cyst aspiration. The hyperdense cyst is correlated with hyperviscosity ${ }^{[5}$, 6].

El Khoury et al ${ }^{[7]}$ noted that $89 \%$ of hyperdense cysts had difficulty in aspiration, while $31 \%$ of hypodense cysts had easy aspiration; the more the hyperdensity, the more difficulty of its aspiration. In the same study, there was no correlation between the cyst MRI signals and the difficulty of cyst resection. Several therapeutic options have been developed for its treatment: non-surgical treatment with control of sequential images, shunting of cerebrospinal fluid [CSF], stereotactic aspiration of its content, microsurgical removal, stereotactic guided endoscopy, neuroendoscopy, stereotactically-guided and neuronavigationassisted endoscopy ${ }^{[8,9]}$.

Shunting is not recommended due to frequent complications related to valves and the surgical techniques in the bilateral obstruction of the foramen of Monro. It requires bilateral shunting and it is not a curative option. Open surgical excision of the colloid cyst was first successfully carried out by Walter Dandy in 1921. Methods were developed over time and microsurgical techniques become the gold standard for total removal by many authors ${ }^{[5,10]}$.
The transcortical, the transcallosal and the infratentorial-supracerebellar approaches are the traditional techniques proposed for their removal ${ }^{[11]}$.

Several endoscopic approaches were proposed to cyst resection. Among them, the transventricular transforaminal technique is the mostly used. The cyst was excised through the foramen of Monro. In the transventricular-trans-choroidal approach, choroidal fissure is opened to access the third ventricle. It is indicated for the sufficiently invisible cysts within the lateral ventricle through a small foramen of Monro ${ }^{[12]}$.

As part of the endoscopic procedure, the selection of an entry point is of crucial importance. The determination of the entry point and trajectory determines the suitable endoscope approach. Recognizing a good entry point and trajectory facilitates the procedure, and helps the avoidance of jeopardizing the key anatomical structures [e.g., the caudate nucleus, deep cerebral veins, and the fornices]. Intraoperative fornix trauma could result from pressure on this structure or swinging the scope laterally or anteroposteriorly, during the access to or removal of the lesion. The effect of this damage on memory ranged from imperceptible to disabling. These complications can be reduced by proper selectin of optimal entry point that traverses the Monro foramen without the need to swing the endoscope back and forth or from side to side ${ }^{[13]}$.

Gross-total resection [GTR] can also be achieved by careful selection of an optimal trajectory. However, the trajectory selection to the colloid cyst differs greatly in the previous literature. The risk of traumatizing important anatomical structures around the pathway and the chance of leaving residual cyst can be minimized by proper definition of the ideal entry point and trajectory from a technical perspective. The reported complications after colloid cyst resection were intraoperative hemorrhage, memory deficit, mutism, third cranial nerve palsy, ventriculitis, seizures, venous infarction, fornix and thalamus contusion, transient or permanent hemiparesis and subdural fluid accumulation ${ }^{[14,15]}$.

\section{THE AIM OF THE WORK}

The current work aimed to assess the outcome of endoscopic excision of the third ventricular colloid cyst through resolution of symptoms [if present], extent of excision and rate of complications.

\section{PATIENTS AND METHODS}

This is a retrospective study, carried out at the Department of Neurosurgery, Faculty of Medicine, AlAzhar University [Damietta]. It covered the duration from February 2018 to February 2021. It included 20 subjects with a third ventricular colloid cyst, who managed by an endoscopic excision.

We included all patients of any age, either symptomatic or asymptomatic, with or without 
ventriculomegaly; had extra-ventricular drain [EVD], ventriculoperitoneal shunt [VPS] or not. The exclusion criteria were recurrent third ventricular colloid cyst, superior growth of colloid cysts beyond the level of the roof of the third ventricle and are insinuated between the leaflets of the septum pellucidum. Finally, patients with files containing insufficient data were excluded.

Files were reviewed for preoperative evaluation, which included clinical assessment by history taking and physical [general and neurological] examination. In addition, all underwent ophthalmological examination [fundus visual acuity and visual field assessment]. The radiological investigations comprised pre-and postcontrast CT brain and MRI of the brain to identify the cyst size, site, density and enhancement and the ventricular size. Finally, results of routine pre-operative laboratory assessment [e.g., CBC, INR, serum create, kidney and liver function] were checked and included.

\section{Surgical technique}

All surgeries were completed under general anesthesia, the patient was positioned in the supine position with head elevation 10 to 30 degree on a head rest. The trajectory was built with $\mathrm{CT}$ and MRI aiming to avoid the fornix, internal cerebral vein, and septal veins.
The target is the center of the lesion. The technique was carried out through the right lateral ventricle or through the more enlarged lateral ventricle. We used a rigid neuroendoscope $4 \mathrm{~mm}$ diameter, $30 \mathrm{~cm}$ in length [Karl Storz, Tuttlingen, Germany]. The endoscope was connected to a cable, which was connected to a light source. Digital high definition [HD] video camera connected to high-resolution monitor and a digital recording system was connected to the camera system for video documentation [Figure 1]. The surgical instruments were straight instruments as they can be inserted close to the endoscope along its axis.

The incision was $3 \mathrm{~cm}$ long, longitudinal and parallel to the midline. This was followed by trephine operation. The dura and underlying pia were coagulated with monopolar cautery and perforated. The ventricular perforation and neuroendoscope was inserted into the lateral ventricle. The anatomical landmarks [e.g., septal vein, thalamostriate vein, choroid plexus and the foramen of Monro] were recognized. The cyst capsule was recognized and coagulated. A thin catheter was inserted through the neuroendoscope working channel for aspiration of the cyst colloid content, followed by cyst excision. Finally, hemostasis and closure of the wound was done after insertion of the surgical or gel foam.

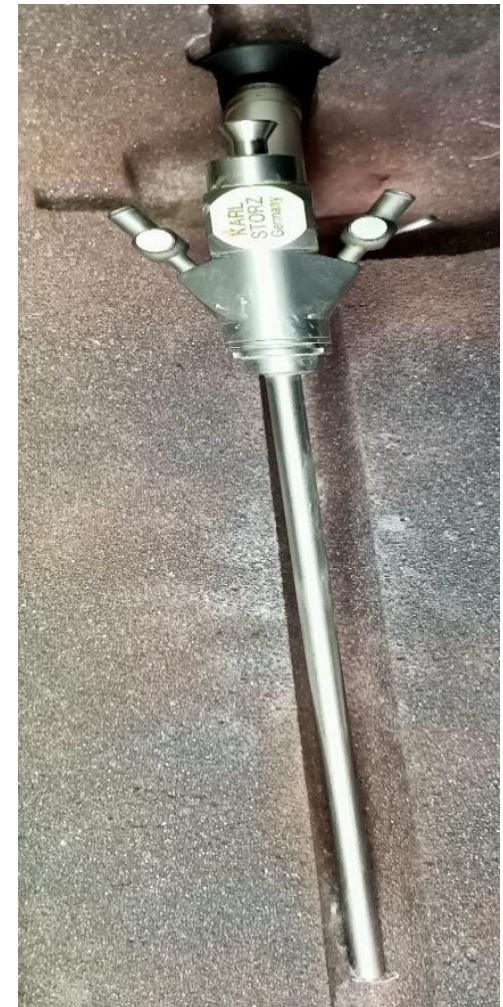

A

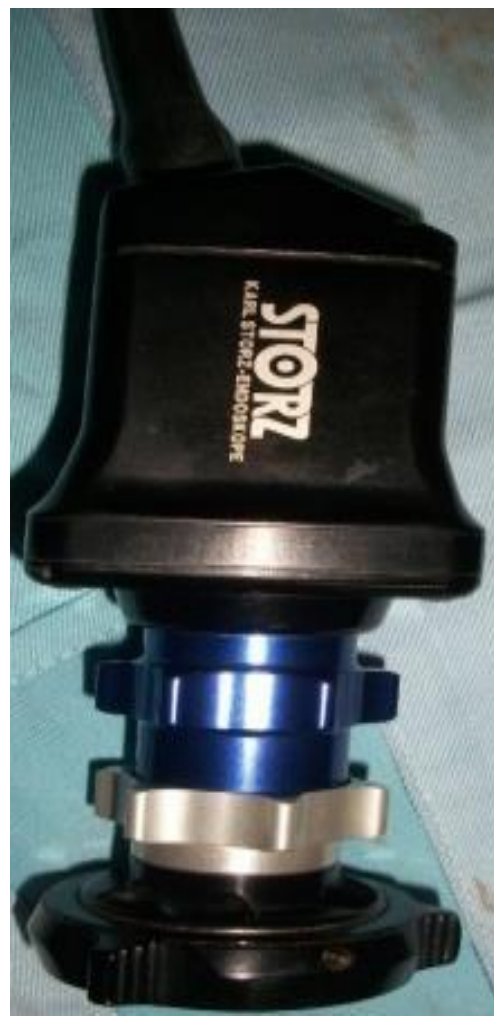

$\mathrm{B}$

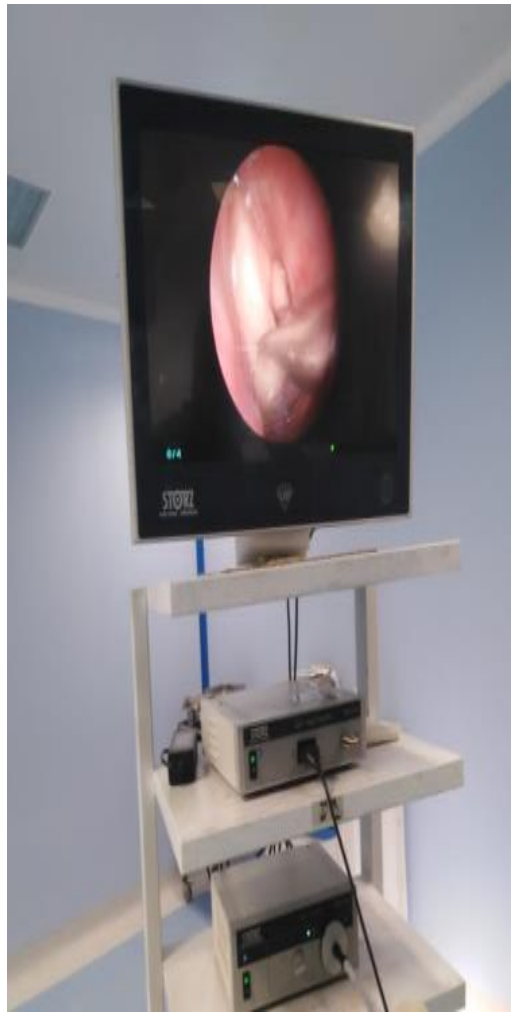

$\mathrm{C}$

Figure [1]: Endoscopic equipment [A] 4-mm neuroendoscope [B] High-definition digital camera [C] Camera unit, Xenon light source. 
Table [1]: Extent of resection of colloid cyst according to BNI scale ${ }^{[16]}$

\begin{tabular}{|l|l|}
\multicolumn{1}{c|}{ Grade } & No surgical or radiological residual \\
\hline BNI [I] & Residual cyst wall visible by the surgeon not seen radiologically \\
\hline BNI [II] & Residual cyst wall visible by the surgeon and radiologically \\
\hline BNI [III] & Removal of the cyst content only or no removal \\
\hline BNI [IV]
\end{tabular}

\section{Postoperative evaluation}

All patients were examined generally and neurologically, with routine follow-up imaging study immediately postoperatively [second postoperative day], at 3 and 6 months postoperatively. We examined all patients searching for recurrence of symptoms, presence of any complications and evaluation of the size of ventricles, presence of hydrocephalus, and degree of cyst excision on CT scan. All patients were graded on Barrow Neurological Institute scale [table 1] ${ }^{[16]}$. At the sixth postoperative month, we asked for MRI of the brain to assess the cyst recurrence rate. The mean follow-up period for all patients in our study was 12 months postoperatively.

\section{Ethical consideration}

The study conducted after approval of the protocol by The Institutional Research and Ethics Committee. An informed written consent had been signed by each patient after full explanation of the procedure. The patients had the right to refuse participation without affecting their medical care. They also had the right to withdraw from the study at any time without penalty. Confidentiality of all data and results was guaranteed, and patients were informed about any abnormal results of procedures. The research was completed according to ethical code of Helsinki declaration and data used in analysis are available on request.

\section{Statistical Analysis}

Data were collected, coded, revised and entered to the Statistical Package for Social Science [IBM SPSS] version 20. The data presented as numbers and percentages for the qualitative data, mean, standard deviations and ranges for the quantitative data. Comparing different methods done by the chi-square test for categorical variables and t- test for continuous variables. Variables presenting significant differences between methods in univariate comparison will be entered in step wise Logistics regression analysis. A two-side $\mathrm{P}$ value of less than 0.05 considered statistically significant.

\section{RESULTS}

Twenty patients with third ventricular colloid cyst were underwent endoscopic resection over three years at Al-Azhar University Hospitals, and followed up for six months in outpatient clinic. The patients' age ranged from 21 to 58 years with mean age of $37.5 \pm 11.3$ years. Twelve patients [60.0\%] were males and $40.0 \%$ were females. All patients had headache at presentation, $60.0 \%$ had vomiting, $80.0 \%$ had blurring of vision, $20.0 \%$ had seizures, $10.0 \%$ had memory deficits and one patient [5.0\%] had not additional symptoms than headache. After clinical examination and different laboratory and radiological investigations, papilledema was recognized among 18 [90.0\%] patients, while hydrocephalus was reported among $75.0 \%$. Finally, the average size of the cyst was ranged between 12 to 21 $\mathrm{mm}$ and the mean $\pm \mathrm{SD}$ was $17.4 \pm 2.66 \mathrm{~mm}$.

Regarding operative data, the total cyst removal BNI scale type 1 was achieved for 17 patients [85.0\%] and partial removal BNI scale type 2 reported for 2 patients [10.0\%] and partial removal BNI Scale type 3 in 1 patient [5\%]. The average intraoperative blood loss ranges from 60 to $120 \mathrm{cc}$ [mean $\pm 90 \pm 30 \mathrm{CC}$ ]. The operative time ranged from 80 to 120 minute with [mean operative time $100 \pm 20$ minute]. Postoperative infections were developed among 4 patients [20.0\%]. Three patients [15\%] had temporary amnesia and 1 patient [5\%] had intra ventricular hemorrhage, which was of mild degree and controlled by irrigation, and was discharged at the fifth day after surgery.

Postoperatively, all symptoms were resolved, except for 3 patients [15\%], two of them [10\%] had mild visual disturbance and one [5\%] had amnesia. The recurrence of the cyst was detected in 2 patients [10\%]. Finally, the duration of hospital stay ranged from 3 to 5 days with [mean \pm SD of $3.5 \pm 1.3$ day]. Next, we present two of our patients.

The first was a 36 years old female, presented with headache, blurring of vision, and repeated vomiting. On clinical examination, she was fully conscious. The fundus examination revealed bilateral papilledema. She was operated upon by endoscopic transfrontal transforaminal approach. Tumor was totally removed and BNI scale was grade I, without any postoperative complications [Figure 2].

The second was a 43 years old male patient, accidentally discovered a third ventricular colloid cyst. He was operated upon by endoscopic transfrontal transforaminal approach. Tumor was totally removed, BNI scale type I without postoperative complications [Figure 3]. 

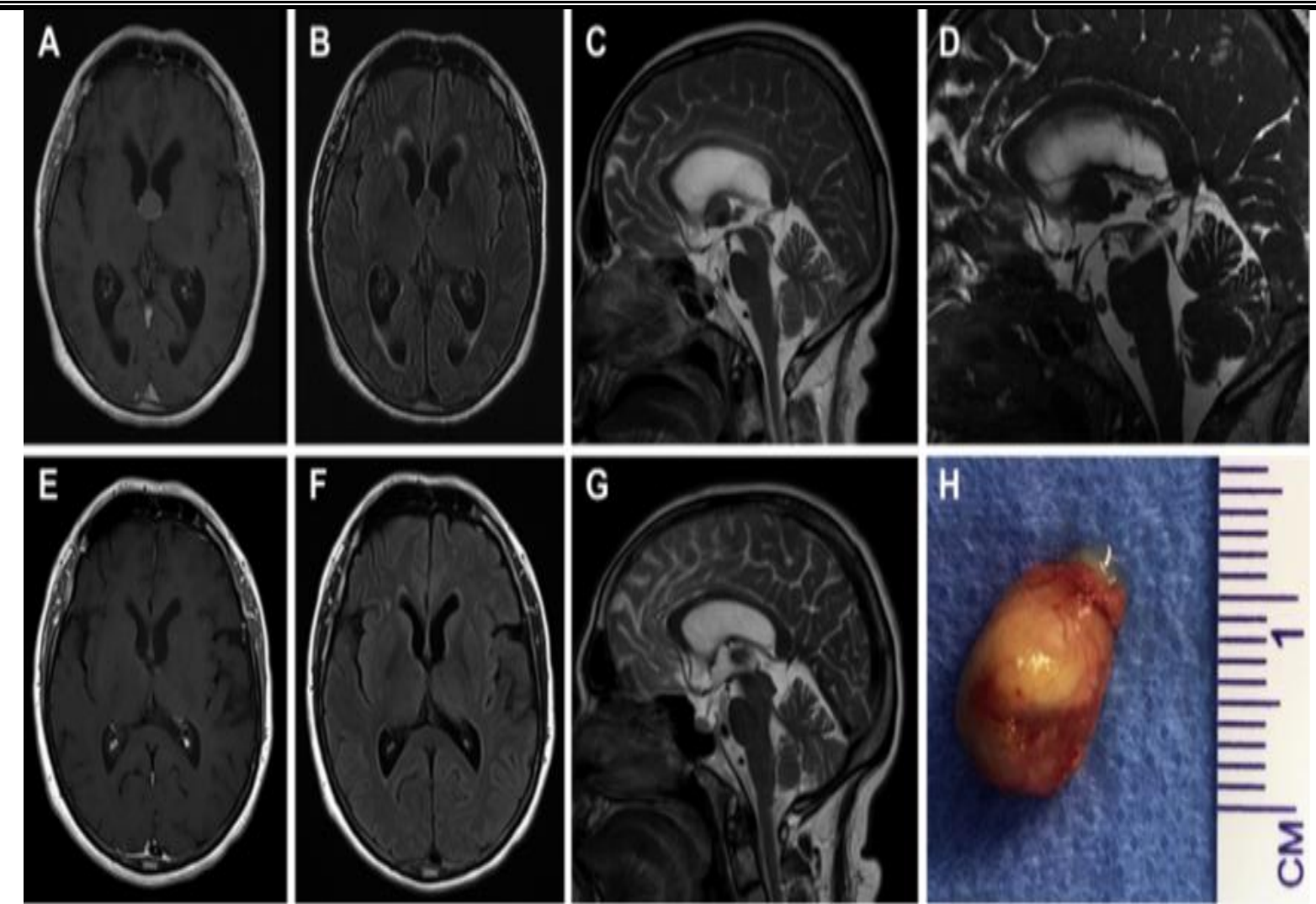

Figure [2]: Preoperative MR images in axial T1 [A], axial T2 fluid-attenuated inversion recovery [B], sagittal T2 [C], and sagittal construction interphase in steady-state [D] sequences. Postoperatively, MR images showed no remnants of on the cyst wall in axial T1 [E], axial T2 fluid-attenuated inversion recovery [F], and sagittal T2 [G] sequences. The grossly removed cyst is demonstrated in $\mathrm{H}$.
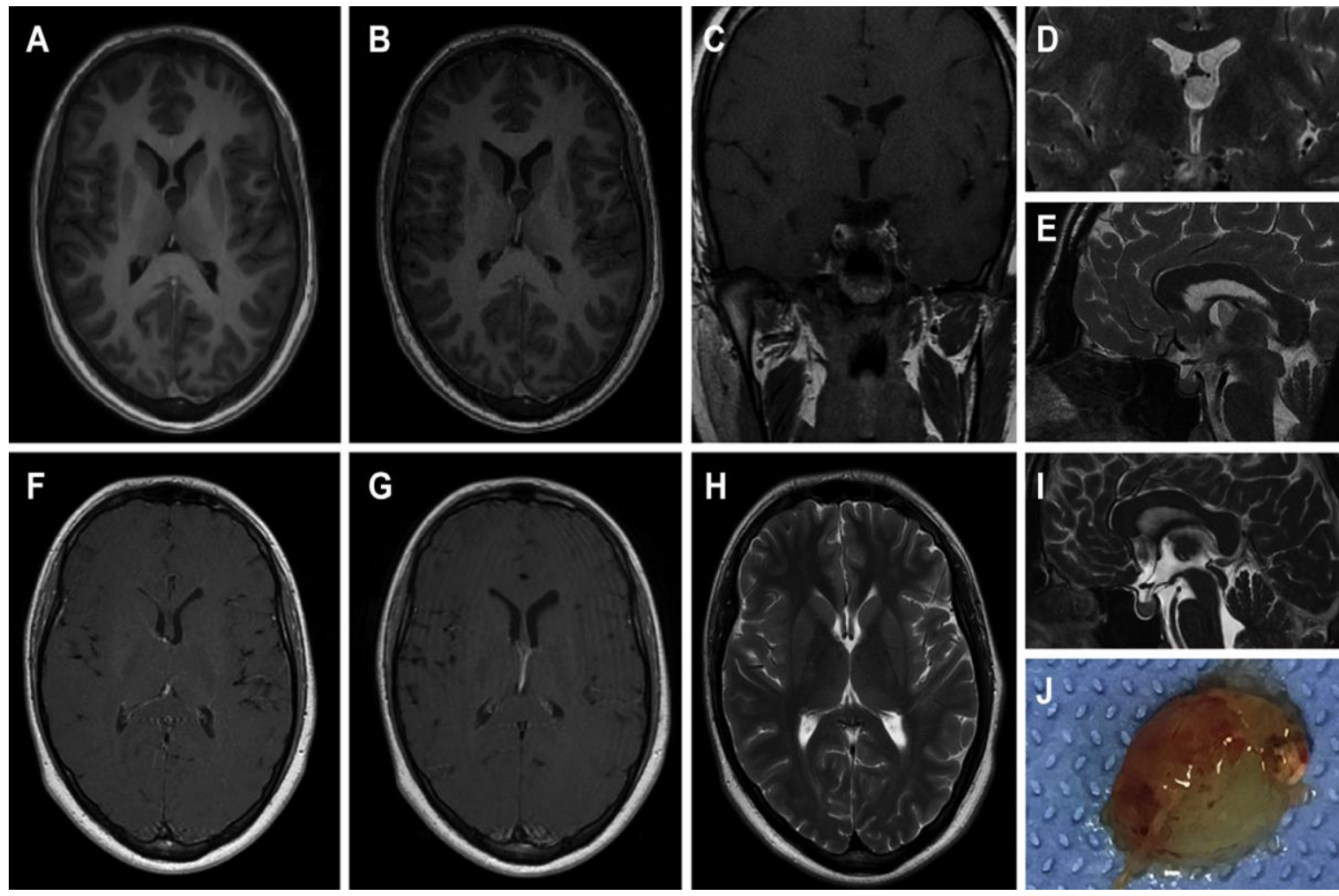

Figure [3]: Preoperative MR images in axial T1 with contrast in two sequential cuts at the level of the third ventricle roof [A and B] and coronal T1 without contrast [C], coronal T2 [D], sagittal T2 [E] sequences.

Postoperatively, MR images showed no remnants in the contrast-enhanced axial T1 images corresponding to images A and B [F and G], and in the axial [H] and sagittal [I] T2-weighted images. The grossly removed cyst is demonstrated in $\mathrm{J}$. 


\section{DISCUSSION}

The current work results can be placed in the long line of clinical evidence of efficacy, safety and utility of the endoscopic techniques and approaches to the cysts of the third ventricular. The Endoscopy is the first line modality for the third ventricle CCs. Neuroendoscopic resection of the colloid cyst can reliably accomplish complete removal of the tumor with a high patient satisfaction level. The principal advantages of endoscopic colloid cyst aspiration are the short operating time, minimally invasive, lower complication rate due to the small cortical incision so no injury to cingulate gyrus or pericallosal arteries, lower risk of a seizure disorder and can be achieved in comparatively less dilated ventricles ${ }^{[17]}$. Continued advancement of endoscopic methods and instruments with good long-term outcome in endoscopically treated colloid cysts have established the endoscopic cyst resection as a reasonable alternative to microsurgical methods ${ }^{[18]}$.

The main goal of endoscopic colloid cyst resection is not just the aspiration of the cyst contents or coagulation of its wall but also the complete or partial removal of cyst capsule. These were become easier by the continuous improvement of endoscopic technologies and instruments ${ }^{[19]}$

Open microsurgical cystectomy was traditionally considered the "gold standard" treatment. However, operative approaches are not without risks.

In the current research males represented [60\%] and females $40 \%$. The average age was 37.5 years. The main clinical manifestations were headache [100\%], blurring of vision [80.0\%] and vomiting [60\%]. The mean cyst size was $17.4 \pm 2.66 \mathrm{~mm}$ and hydrocephalus was discovered in $75 \%$ of the patients. Ibanez-Botella et al. ${ }^{[12]}$ reported higher male percentages [71\%]. The average age of their patients was 39.6 years. On the contrary, Brostigen et al. ${ }^{[20]}$ demonstrated that male patients were $41 \%$. The mean age was 41 years. This could be attributed to different selection criteria and different number of included patients in each study.

In the line with the current study, Ragaee and Ismail [21] reported that, the presenting symptoms were [headache, vomiting, and blurring of vision] [92.9\%], disturbed conscious level [14.3\%], memory deficit [14.3\%], gait disturbance [7.1\%], and incontinence of urine [21.4\%]. These results are in line with the current work. In addition, Samadian et al. ${ }^{[22]}$ reported the presenting symptoms in their series of 112 patients as headache [84.1\%], vomiting [42.2\%], impaired vision [36.3\%], gait instability [23\%], and memory disorder [13.9\%].

The fundus examination revealed papilledema in [ $90 \%$ of the patients. These results agreed with Decq et al. ${ }^{[23]}$, who reported average cyst size of $17 \pm 3 \mathrm{~mm}$, Papilledema and Hydrocephalus in all patients
Regarding outcome of the current work, total resection [BNI type 1] was achieved in $85.0 \%$, intraoperative partial resection without radiological evidence BNI type II reported in $10 \%$ and intraoperative partial resection with radiological evidence of residual BNI type III in one patient [5\%]. These results are in line with Mishra et al. ${ }^{\text {[2] }}$, who reported that, gross total excision was done in $78 \%$ of patients and partial excision and cyst aspiration only in $11 \%$ of patients. In addition, Vorbau et al. ${ }^{[25]}$ retrospectively evaluated 20 patients who underwent endoscopic resection and showed that the technique is a safe and effective modality, with excellent long-term outcome. Dhandapani et al. ${ }^{[26]}$ included 22 patients for endoscopic resection of large colloid cyst. Their mean age was 34 years and the mean diameter of the cyst was $19 \mathrm{~mm}$. Gross total resection [GTR] could be accomplished in all. None had a recurrence, ventriculomegaly, or retreatment.

In our study the postoperative infections were reported for $20 \%, 15 \%$ had mild memory affection and $5 \%$ develop IVH and treated with EVD. The recurrence rate was $10.0 \%$. Isaacs et al. ${ }^{[27]}$ demonstrated that, a complete aspiration of the cyst contents was achieved in $98.6 \%$, with postoperative improvement or stability for all patients. The recurrence rate was $8.1 \%$. No major complications or mortality was reported. These results agree with the current work. Sheikh et al. ${ }^{[28]}$ reported a complications rate of $10.5 \%$, the commonest was seizures, interventricular hemorrhage, memory deficit, venous infarction, subdural hematoma, hemiparesis, and meningitis. The difference in the rate of complication may be related to the small sample size in our study. However, the same group of authors reported a recurrence rate of $3.91 \%$ which is lower than the current study.

Careful patient selection, full general and neurologic examination, deep and through looking on the preoperative investigations and diligent planning of the surgical objectives are key components of a good outcome. Enrolling more patients, preferably through multicenter studies will help set clear selection criteria for each of the endoscopic intervention and establish prognostic factors for third ventricular lesions endoscopically managed.

\section{Conclusion}

Endoscopic excision of colloid cysts is an effective, safe and reliable technique with established learning curve that offers many advantages: Short operative time, short hospital stays, minimal blood loss, minimal brain retraction, full surgical excision and early return to work.

Financial and Non-financial Relationships and Activities of Interest

None 


\section{REFERENCES}

1. Barbagallo GM, Raudino G, Visocchi M, Maione M, Certo F. Outof-third ventricle colloid cysts: review of the literature on pathophysiology, diagnosis and treatment of an uncommon condition, with a focus on headache. J Neurosurg Sci. 2019 Jun;63[3]:330-336. DOI: 10.23736/ S0390-5616.16.03831-5.

2. Kabashi A, Dedushi K, Ymeri L, Ametxhekaj I, Shatri M. Colloid Cyst of the Third Ventricle: Case report and Literature Review. Acta Inform Med. 2020 Dec;28[4]: 283-286. DOI: 10.5455/aim.2020.28.283-286

3. Beaumont TL, Limbrick DD Jr, Rich KM, Wippold FJ 2nd, Dacey RG Jr. Natural history of colloid cysts of the third ventricle. J Neurosurg. 2016 Dec;125[6]:1420-1430. DOI: 10.3171/2015.11. JNS151396.

4. O'Neill AH, Gragnaniello C, Lai LT. Natural history of incidental colloid cysts of the third ventricle: A systematic review. J Clin Neurosci. $2018 \quad$ Jul; $\quad 53: 122-126 . \quad$ DOI: 10.1016/j.jocn.2018.04.061.

5. Yadav YR, Yadav N, Parihar V, Kher Y, Ratre S. Management of colloid cyst of third ventricle. Turk Neurosurg. 2015;25[3]:36271. DOI: $10.5137 / 1019-5149 . J T N .11086-14.1$.

6. Uno T, Hayashi Y, Sasagawa Y, Miyamori T, Oishi M, Nakada M. A suprasellar colloid cyst over an 11-year follow-up: case report and literature review. World Neurosurg. 2019 Jan 18: S18788750[18]32828-6. DOI: 10.1016/j.wneu.2018.11.258.

7. El Khoury C, Brugières P, Decq P, Cosson-Stanescu R, Combes C, Ricolfi F, Gaston A. Colloid cysts of the third ventricle: are MR imaging patterns predictive of difficulty with percutaneous treatment? AJNR Am J Neuroradiol. 2000 Mar;21[3]:489-92. PMID: 10730640 .

8. Heller RS, Heilman CB. Colloid Cysts: Evolution of Surgical Approach Preference and Management of Recurrent Cysts. Oper Neurosurg [Hagerstown]. 2020 Jan 1;18[1]:19-25. DOI: 10.1093/ons/opz059.

9. Haider G, Laghari AA, Shamim MS. Choosing between endoscopic or microscopic removal of third ventricle colloid cysts. J Pak Med Assoc. 2017 Sep;67[9]:1458-1459. PMID: 28924297.

10. Hellwig D, Bauer BL, Schulte M, Gatscher S, Riegel T, Bertalanffy $\mathrm{H}$. Neuroendoscopic treatment for colloid cysts of the third ventricle: the experience of a decade. Neurosurgery. 2003;52[3]:525-33; discussion 532-3. DOI: 10.1227/01.neu.0000047671.27057.55

11. Konovalov AN, Pitskhelauri DI. Infratentorial supracerebellar approach to the colloid cysts of the third ventricle. Neurosurgery. 2001 Nov;49[5]:1116-22; discussion 1122-3. DOI: 10.1097/00006123-200111000-00019.

12. Ibáñez-Botella G, Segura M, De Miguel L, Ros B, Arráez MÁ. Purely neuroendoscopic resection of intraventricular tumors with an endoscopic ultrasonic aspirator. Neurosurg Rev. 2019 Dec;42[4]:973-982. DOI: 10.1007/ s10143-018-1011-8.

13. Chen F, Nakaji P. Optimal entry point and trajectory for endoscopic third ventriculostomy: evaluation of 53 patients with volumetric imaging guidance. J Neurosurg. 2012 May;116[5]:1153-7. DOI: 10.3171/2012.2. JNS111287.

14. Tirakotai W, Schulte DM, Bauer BL, Bertalanffy H, Hellwig D. Neuroendoscopic surgery of intracranial cysts in adults. Childs Nerv Syst. 2004 Nov;20[11-12]:842-51. DOI: 10.1007/s00381004-0941-3.

15. Eshra MA. Endoscopic management of third ventricular colloid cysts in mildly dilated lateral ventricles. Neurosurg Rev. 2019 Mar; 42[1]:127-132. DOI: 10.1007/s10143-018-0956-y.
16. Hostettler IC, Sebök M, Ambler G, Muroi C, Prömmel P, Neidert MC, et al. Validation and Optimization of Barrow Neurological Institute Score in Prediction of Adverse Events and Functional Outcome After Subarachnoid Hemorrhage-Creation of the HATCH [Hemorrhage, Age, Treatment, Clinical State, Hydrocephalus] Score. Neurosurgery. 2020 Dec 15;88[1]:96105. DOI: $10.1093 /$ neuros/ nyaa316.

17. Rangel-Castilla L, Chen F, Choi L, Clark JC, Nakaji P. Endoscopic approach to colloid cyst: what is the optimal entry point and trajectory? J Neurosurg. 2014 Oct;121[4]:790-6. DOI: 10.3171/2014.5. JNS132031.

18. Stachura K, Grzywna E, Krzyżewski RM, Kwinta BM. Retrospective evaluation of endoscopic treatment in colloid cyst of the third ventricle. Wideochir Inne Tech Maloinwazyjne. 2021 Sep;16[3]:604-611. DOI: 10.5114/ wiitm.2021.103957.

19. Zymberg ST, Riechelmann GS, da Costa MDS, Ramalho CO, Cavalheiro S. Third ventricle colloid cysts: An endoscopic case series emphasizing technical variations. Surg Neurol Int. 2021 Jul 27; 12:376. DOI: 10.25259/SNI_446_2021.

20. Brostigen CS, Meling TR, Marthinsen PB, Scheie D, Aarhus M, Helseth E. Surgical management of colloid cyst of the third ventricle. Acta Neurol Scand. 2017 Apr; 135[4]:484-487. DOI: 10.1111/ane.12632.

21. Ragaee M, Ismail K. Endoscopic surgical excision of third ventricular colloid cyst in Upper Egypt: results of 2 years of practice. J Current Med Res Pract. 2020;5[1]:27-31. DOI: 10.4103/JCMRP.JCMRP_156_19.

22. Samadian M, Ebrahimzadeh K, Maloumeh EN, Jafari A, Sharifi G, Shiravand S, Digaleh H, Rezaei O. Colloid Cyst of the Third Ventricle: Long-Term Results of Endoscopic Management in a Series of 112 Cases. World Neurosurg. 2018 Mar;111: e440e448. DOI: 10.1016/j.wneu.2017.12.093.

23. Decq P, Le Guerinel C, Brugières P, Djindjian M, Silva D, Kéravel Y, Melon E, Nguyen JP. Endoscopic manage-ment of colloid cysts. Neurosurgery. 1998 Jun;42[6]: 1288-94; discussion 12946. DOI: $10.1097 / 00006123-199806000-00051$.

24. Mishra S, Chandra PS, Suri A, Rajender K, Sharma BS, Mahapatra AK. Endoscopic management of third ventricular colloid cysts: eight years' institutional experience and description of a new technique. Neurol India. 2010 May-Jun;58[3]:412-7. DOI: 10.4103/0028-3886.66222.

25. Vorbau C, Baldauf J, Oertel J, Gaab MR, Schroeder HWS. LongTerm Results After Endoscopic Resection of Colloid Cysts. World Neurosurg. 2019 Feb;122:e176-e185. DOI: 10.1016/j.wneu.2018.09.190.

26. Dhandapani S, Verma R, Mohanty M, Sharma A, Vyas S, Dhandapani M, Gupta SK. Colloid cysts: Neuropsychological outcome, quality of life and long-term control after endoscopic gross total resection. Clin Neurol Neurosurg. 2021 Oct; 209:106951. DOI: 10.1016/j.clineuro.2021.106951.

27. Isaacs AM, Bezchlibnyk YB, Dronyk J, Urbaneja G, Yong H, Hamilton MG. Long-Term Outcomes of Endoscopic Third Ventricle Colloid Cyst Resection: Case Series with a Proposed Grading System. Oper Neurosurg [Hagerstown]. 2020 Aug 1;19[2]:134-142. DOI: 10.1093/ons/opz409.

28. Sheikh AB, Mendelson ZS, Liu JK. Endoscopic versus microsurgical resection of colloid cysts: a systematic review and meta-analysis of 1,278 patients. World Neurosurg. 2014 Dec;82[6]:1187-97. DOI: 10.1016/j.wneu.2014.06.024. 


\section{2) 12022}

international Journal https://ijma.journals.ekb.egl Print ISSN: 2636-4174 Online ISSN: 2682-3780

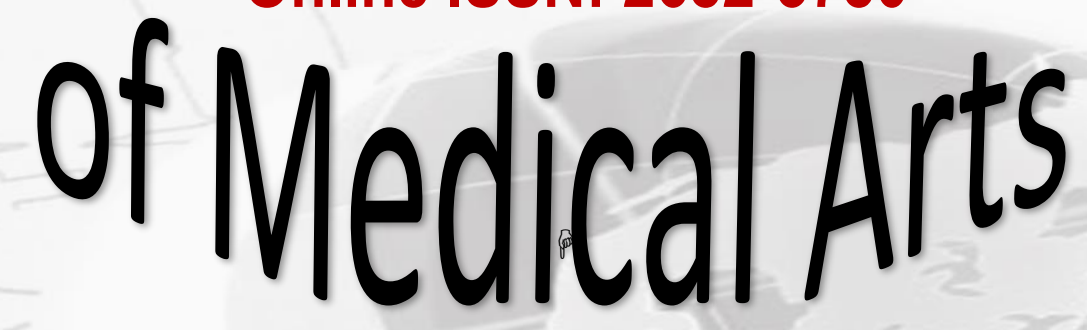

